\title{
Author Correction: Immunogenomic profiling determines responses to combined PARP and PD-1 inhibition in ovarian cancer
}

Anniina Färkkilä (D), Doga C. Gulhan, Julia Casado (D), Connor A. Jacobson (1D, Huy Nguyen (1D, Bose Kochupurakkal, Zoltan Maliga, Clarence Yapp (D, Yu-An Chen (D), Denis Schapiro, Yinghui Zhou, Julie R. Graham (D, Bruce J. Dezube, Pamela Munster (1), Sandro Santagata (1D, Elizabeth Garcia, Scott Rodig, Ana Lako, Dipanjan Chowdhury (D), Geoffrey I. Shapiro, Ursula A. Matulonis, Peter J. Park (1D, Sampsa Hautaniemi (D, Peter K. Sorger (1D, Elizabeth M. Swisher (1), Alan D. D'Andrea (1) \& Panagiotis A. Konstantinopoulos

Correction to: Nature Communications https://doi.org/10.1038/s41467-020-15315-8, published online 19 March 2020.

The original version of this Article omitted the following from the Acknowledgements:

This research was also supported by the Ludwig Center at Harvard and U54-CA225088 to Peter Sorger, BioEntrepreneur-Fellowship of the University of Zurich, reference no. BIOEF-17-001 and Early Postdoc Mobility fellowship (no. P2ZHP3_181475) to Denis Schapiro.

The original version of this Article contained errors in the author affiliations.

Peter J. Park was incorrectly associated with Dana-Farber Cancer Institute, 450 Brookline Avenue, Boston, MA 02215, USA. The affiliation of Peter J. Park with Department of Biomedical Informatics, Harvard Medical School, 25 Shattuck Street, Boston, MA, 02115, USA was inadvertently omitted. This has now been corrected in both the PDF and HTML versions of the Article.

Published online: 18 May 2020

\footnotetext{
(c) Open Access This article is licensed under a Creative Commons Attribution 4.0 International License, which permits use, sharing, adaptation, distribution and reproduction in any medium or format, as long as you give appropriate credit to the original author(s) and the source, provide a link to the Creative Commons license, and indicate if changes were made. The images or other third party material in this article are included in the article's Creative Commons license, unless indicated otherwise in a credit line to the material. If material is not included in the article's Creative Commons license and your intended use is not permitted by statutory regulation or exceeds the permitted use, you will need to obtain permission directly from the copyright holder. To view a copy of this license, visit http://creativecommons.org/licenses/by/4.0/.
}

(C) The Author(s) 2020 